\title{
Design of Model Reference Adaptive control and Nonlinear PI Controller for Continuous Stirred Tank Reactor
}

\author{
S. Anbu \\ Assistant Professor \\ Dept of Instrumentation Engg \\ Annmalai University
}

\author{
N. Jaya \\ Associate Professor \\ Dept of Instrumentation Engg \\ Annmalai University
}

\begin{abstract}
The Conventional control approach may not be suitable for non-linear systems and for the systems with considerable parameter variations over a period of time. On the other hand adaptive control techniques proved to be a convenient tool in dealing with the above said systems. The Model Reference Adaptive Systems (MRAS) with performance specifications given in terms of reference model is tried for Continuous Stirred Tank Reactor. The MIT rule is used as adaptation algorithm and the performances are compared with the conventional PI controller through simulation.
\end{abstract}

\section{General Terms}

Process Control, Adaptive Control.

\section{Keywords}

Adaptive Control, Conventional PI,MIT rule, MRAS.

\section{INTRODUCTION}

Almost all the industrial process parameters changes over time for various reasons like equipment change, change in operating conditions of the units, change in market demand. Consequently, a conventional control technique may not provide effective control of complex processes where process parameter changes can occur significantly, but cannot be measured or anticipated.[1] The classical control methods are normally a feedback method relies on monitoring the change in the PV with respect to the set point and control designed for worst case conditions. Alternatively, adaptive control strategies are available where controller parameters and/or control structure are modified online as conditions change.

In this paper, a Model Reference Adaptive Systems is designed making use of MIT rule.The MIT rule is the original approach to adaptive control uses gradient approach to change the controller gain to minimize the error between plant and the model.[2]

The continuous Stirred Tank Reactor (CSTR) is one of the versatile reactor find its application in many chemical industries, exhibit reasonably high nonlinear behavior. Hence a CSTR modeling and its multiple operating conditions are studied and MRAS concepts are demonstrated through extensive simulation.

\section{THE MODEL REFERENCE ADAPTIVE CONTROL}

All The basic philosophy of designing a linear controller (in a deterministic environment) assumes knowledge of the plant dynamic model and of the desired performances. In most cases the desired performances of the feedback control system can be specified in terms of the characteristics of a dynamic system that is a "realization" of the desired behavior of the closed-loop system. For example, a tracking objective can be specified in terms of the desired input-output behavior by a given transfer function.[2] A regulation objective can be specified in terms of the evolution of the output starting from an initial disturbed value by specifying the desired pole location of the closed loop (i.e., by a given transfer function). The controller is designed such that for a given plant model the closed-loop control system has the characteristics of the desired dynamic system.[3]

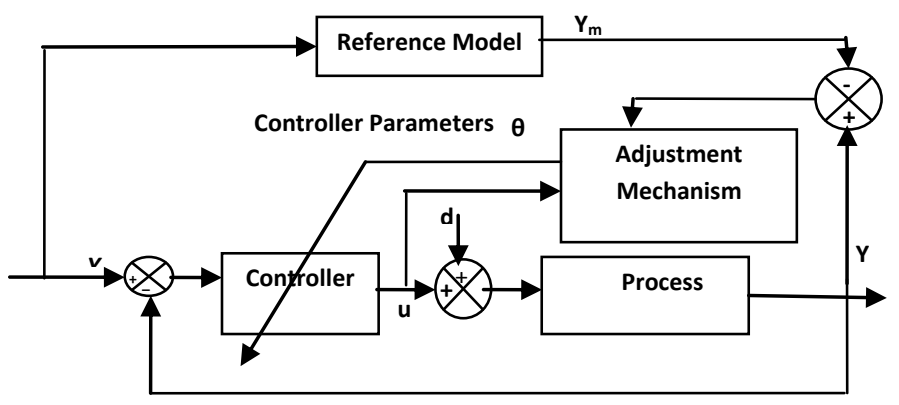

Fig 1: Block Diagram of Model Reference Adaptive systems

The controller is now designed such that (1) the error between the output of the plant and the output of the reference model is identically zero for identical conditions, and (2) an initial error will vanish with a certain dynamics. When the plant parameters are unknown or change with time, in order to achieve the desired performances an adaptive control approach has to be considered. The Fig.1 shows the block diagram of MRAS. The reference model is the realization of system with the desired performance. This scheme is based on the observation that the difference between the output of the plant and the output of the reference model (subsequently called plant-model error) is a measure of the difference between the real and the desired performance. This information is used through the adaptation mechanism (which also receives other information) to adjust the parameters of the controller automatically in order to force asymptotically the plant-model error to zero.

\section{THE GRADIENT METHOD FOR MRAC}

To present the Gradient method also known as MIT rule, consider a closed-loop system in which the controller has one adjustable parameter $\theta$. The desired closed-loop response is specified by a model whose output is ym. Let e be the error 
between the output $y$ of the closed-loop system and the output $\mathrm{ym}$ of the model. One possibility is to adjust parameters in such a way that the loss function

$$
J(\theta)=\frac{1}{2} e^{2}
$$

is minimized. To make $\mathrm{J}$ small, it is sensible to shift the parameters in the direction of the negative gradient of $\mathrm{J}$, that is,

$$
\frac{\mathrm{d} \theta}{\mathrm{dt}}=-\gamma \frac{\partial \mathrm{J}}{\partial \theta}=-\gamma \mathrm{e} \frac{\partial \mathrm{e}}{\partial \theta}
$$

The partial derivative $\frac{\partial \mathrm{e}}{\partial \theta}$, which is called the sensitivity derivative of the system, tells how the error is influenced by the adjustable parameter. If it is assumed that the parameter changes are slower than the other variables in the system, then the derivative $\frac{\partial \mathrm{e}}{\partial \theta}$, can be evaluated under the assumption that $\theta$ is constant.

Usually the reference model is assumed as a first order system with a differential equation shown below

$$
\frac{d y_{m}}{d t}=-a_{m} y_{m}+b_{m} u_{c}
$$

the process to be controlled is described as a first order model

$$
\frac{\mathrm{dy}}{\mathrm{dt}}=-\mathrm{ay}+\mathrm{bu}
$$

Let the controller be

$$
u(t)=\theta_{1} u_{c}(t)-\theta_{2} y(t)
$$

The controller has two parameters. If they are chosen to be

$$
\begin{aligned}
& \theta_{1}=\theta_{1}^{0}=\frac{\mathrm{b}_{\mathrm{m}}}{\mathrm{b}} \\
& \theta_{2}=\theta_{2}^{0}=\frac{\mathrm{a}_{\mathrm{m}}-\mathrm{a}}{\mathrm{b}}
\end{aligned}
$$

the input-output relations of the system and the model are the same. This is called perfect model-following. To apply the MIT rule, introduce the error

$$
\mathrm{e}=\mathrm{y}-\mathrm{y}_{\mathrm{m}}
$$

Where y denotes the output of the closed-loop system. It follows from the model and plant Equations that

$$
\mathrm{y}=\frac{\mathrm{b}}{\mathrm{p}+\mathrm{a}+\mathrm{b} \theta_{2}} \mathrm{u}_{\mathrm{c}}
$$

Where, $p=\frac{d}{d t}$ is the differential operator. The sensitivity derivatives are obtained by taking partial derivatives with respect to the controller parameters $\theta_{1}$ and $\theta_{2}$

$$
\begin{gathered}
\frac{\partial \mathrm{e}}{\partial \theta_{1}}=\frac{\mathrm{b}}{\mathrm{p}+\mathrm{a}+\mathrm{b} \theta_{2}} \mathrm{u}_{\mathrm{c}} \\
\frac{\partial \mathrm{e}}{\partial \theta_{2}}=\frac{\mathrm{b}^{2}}{\left(\mathrm{p}+\mathrm{a}+\mathrm{b} \theta_{2}\right)^{2}} \mathrm{u}_{\mathrm{c}}=-\frac{\mathrm{b}}{\mathrm{p}+\mathrm{a}+\mathrm{b} \theta_{2}} \mathrm{y}
\end{gathered}
$$

These formulas cannot be used directly because the process parameters $a$ and $b$ are not known. They can be found through approximations. One possible approximation is based on the observation that $\mathrm{p}+\mathrm{a}+\mathrm{b} \theta_{2}=\mathrm{p}+\mathrm{a}_{\mathrm{m}}$, when the parameters give perfect model-following. Thus the approximation $\mathrm{p}+\mathrm{a}+\mathrm{b} \theta_{2} \approx \mathrm{p}+\mathrm{a}_{\mathrm{m}}$ is used, which will be reasonable when parameters are close to their correct values. With this approximation the following equations are obtained for updating the controller parameters:

$$
\frac{d \theta_{1}}{d t}=-\gamma\left(\frac{a_{m}}{p+a_{m}} u_{c}\right) e
$$

$$
\frac{\mathrm{d} \theta_{2}}{\mathrm{dt}}=\gamma\left(\frac{\mathrm{a}_{\mathrm{m}}}{\mathrm{p}+\mathrm{a}_{\mathrm{m}}} \mathrm{y}\right) \mathrm{e}
$$

The second order reference model is chosen based on the expected closed loop behavior of the system by considering general second order transfer function:

$$
G_{m}(s)=\frac{\omega_{n}^{2}}{s^{2}+2 \omega_{n} \zeta s+\omega_{n}^{2}}
$$

The damping coefficient $\zeta$ and the natural frequency $\omega_{n}$

are computed based on the desired overshoot and settling time of closed loop system.

For temperature control of CSTR, the allowable Peak overshoot $\mathrm{M}_{\mathrm{p}}$ is chosen as $5 \%$ and settling time $\left(\mathrm{T}_{\mathrm{s}}\right)$ is chosen based on the open loop time constant of the system.

The damping coefficient and natural frequency are given by[4]

$$
\zeta=\frac{\ln \left(\frac{\mathrm{M}_{\mathrm{p}}}{100}\right)}{-\pi} \sqrt{\frac{1}{1+\left(\frac{\ln \left(\frac{\mathrm{M}_{\mathrm{p}}}{100}\right)}{-\pi}\right)^{2}}}
$$

and

$\omega_{\mathrm{n}}=\frac{3}{\mathrm{~T}_{\mathrm{s}} \zeta}$

From the above equations the reference model is computed as

$$
G_{m}=\frac{16.32}{s^{2}+5.4 s+16.32}
$$

\section{SIMULATION RESULTS \\ 4.1 The Continuous Stirred Tank Reactor}

The mathematical model of this reactor comes from balances inside the reactor. Notice that, a jacket surrounding the reactor also has feed and exit streams. The jacket is assumed to be perfectly mixed. Energy passes through the reactor walls into the jacket, removing the heat generated by the reaction. The control objective is to maintain the temperature of the reacting mixture $\mathrm{T}$, constant at the desired value .The only manipulated variable is the coolant or jacket temperature.

A simplified modeling equation for a CSTR can be obtained by making following assumptions:

1. Perfect mixing inside reactor and jacket

2. Constant volume reactor and jacket

3. Constant parameter values

In addition, to develop a simplified model, it is assumed that the jacket temperature can be directly manipulated. This assumption is very good, if a boiling heat transfer fluid is used, for example; changing the pressure on the jacket side would result in an instantaneous change in jacket temperature. Even for the re-circulating heat transfer system, the presumption of the jacket temperature being directly manipulated can be beneficial if the jacket dynamics are rapid compared to the reactor dynamics. The following dynamic equations of CSTR are obtained [5]

$$
\begin{aligned}
& \frac{d C_{A}}{d t}=f_{1}\left(C_{A}, T\right)=\frac{F}{V}\left(C_{A F}-C_{A}\right)-K_{0} \exp \left(\frac{-E_{a}}{R(T+460)}\right) C_{A} \\
& \frac{d T}{d t}=f_{2}\left(C_{A}, T\right)=\frac{F}{V}\left(T_{f}-T\right)+\left(\frac{-\Delta H}{\rho C_{p}}\right) K_{0} \exp \left(\frac{-E_{a}}{R(T+460)}\right) C_{A}-\frac{U A}{V \rho C_{p}}\left(T-T_{j}\right)
\end{aligned}
$$


A simple irreversible exothermic reaction $\mathrm{A} \rightarrow \mathrm{B}$ is assumed in the CSTR. The concentration $\left(\mathrm{C}_{\mathrm{A}}\right)$ of a product inside the reactor is assumed to be a function of temperature (T) in the reactor. Also, it is assumed that, the jacket temperature $\left(T_{j}\right)$ is considered as a manipulated variable and the reactor temperature $(\mathrm{T})$ is the controlled variable.

The steady state characteristic of a physical non-linear model of a CSTR is obtained for various values of jacket temperature $\left(\mathrm{T}_{\mathrm{j}}\right)$.The Table. 1 shows the model parameter and operating point assumption for CSTR model equation.

Table 1. Model Parameters and assumption

\begin{tabular}{|c|c|}
\hline $\mathbf{E}_{\mathbf{a}}$ & $32400 \mathrm{BTU} / \mathrm{lbmol}$ \\
\hline $\mathbf{k}_{\mathbf{0}}$ & $15312 \mathrm{hr}-1$ \\
\hline $\mathbf{d H}$ & $-45000 \mathrm{BTU} / \mathrm{lbmol}$ \\
\hline $\mathbf{U}$ & $75 \mathrm{BTU} / \mathrm{hr}-\mathrm{ft} 2-\mathrm{oF}$ \\
\hline $\mathbf{R}$ & $1.987 \mathrm{BTU} / \mathrm{lbmoloF}$ \\
\hline $\mathbf{V}$ & $750 \mathrm{ft} 3$ \\
\hline $\mathbf{F}$ & $3000 \mathrm{ft} 3 / \mathrm{hr}$ \\
\hline Caf & $0.132 \mathrm{bmol} / \mathrm{ft} 3$ \\
\hline Tf & $60 \mathrm{oF}$ \\
\hline $\mathbf{A}$ & $1221 \mathrm{ft} 2$ \\
\hline
\end{tabular}

The steady state response of the CSTR with multiple operating points, which impose complication in the controller design, is shown in the Fig 2

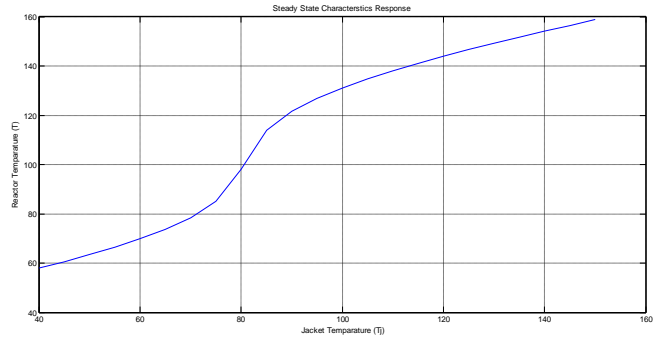

Fig:2 The steady state characteristics of CSTR showing multiple operating regimes.

Table 2. The open loop transfer function models of the CSTR and their corresponding PI controller

\begin{tabular}{|c|c|c|c|}
\hline $\begin{array}{c}\text { SI. } \\
\text { No }\end{array}$ & $\begin{array}{c}\text { Operating } \\
\text { Regions } \\
(\mathbf{0} \text { })\end{array}$ & $\begin{array}{c}\text { Transfer Function } \\
\text { Model }\end{array}$ & $\begin{array}{c}\text { Controller } \\
\text { Settings }\end{array}$ \\
\hline 1 & $40-80$ & $\frac{1}{\mathbf{0 . 6 s}+1}$ & $\begin{array}{c}\mathrm{Kc}=1 \\
\mathbf{T i}=\mathbf{0 . 6 5}\end{array}$ \\
\hline 2 & $\mathbf{8 0 - 1 2 0}$ & $\frac{16.32}{\mathbf{5 c}}$ & $\begin{array}{c}\mathrm{Kc}=1.65 \\
\mathbf{T i}=\mathbf{0 . 3 3} \\
\mathbf{T d}=\mathbf{0 . 6 8}\end{array}$ \\
\hline 3 & $\mathbf{1 2 0 - 1 6 0}$ & $\mathbf{0 . 4 8}$ & $\begin{array}{c}\mathrm{Kc}=2.08 \\
\mathbf{T i}=\mathbf{0 . 1 2}\end{array}$ \\
\hline
\end{tabular}

\subsection{Nonlinear PI Controller}

Making use of transfer function models available at various operating regions, a corresponding PI controller was designed based on IMC tuning procedure. The average of controller gains obtained at various operating regions is taken. The setpoint perturbations are given in such a way to study the closed loop behavior of CSTR in all the operating regions[6].

\subsection{Model Reference Adaptive Control}

A Model Reference Adaptive controller is designed based on the explanation provided in the section 3 and the performance is evaluated through extensive simulation for a CSTR using
MATLAB/SIMULINK software. The adaptation laws are developed based on Gradient methods. A first order and second order reference models are assumed for those methods.

The open loop response of the CSTR at various operating points is shown Fig:.3 and the corresponding transfer function models are given in Table. 2

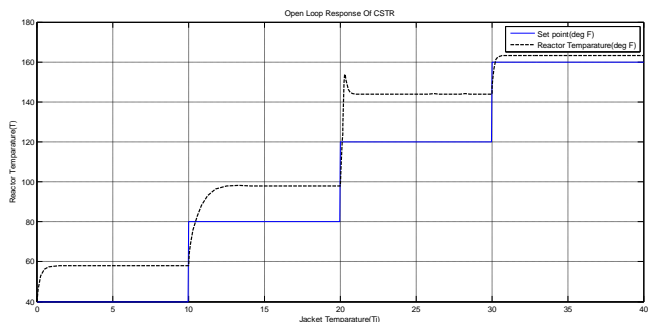

Fig:3 The open loop response of CSTR

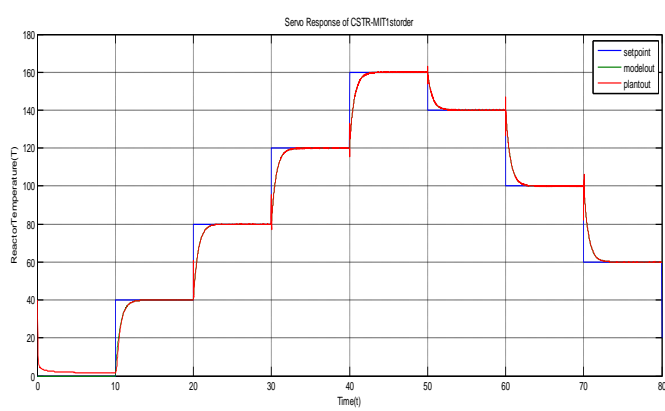

Fig: 4 Servo response of an MRAS with MIT rule with 1st order reference model

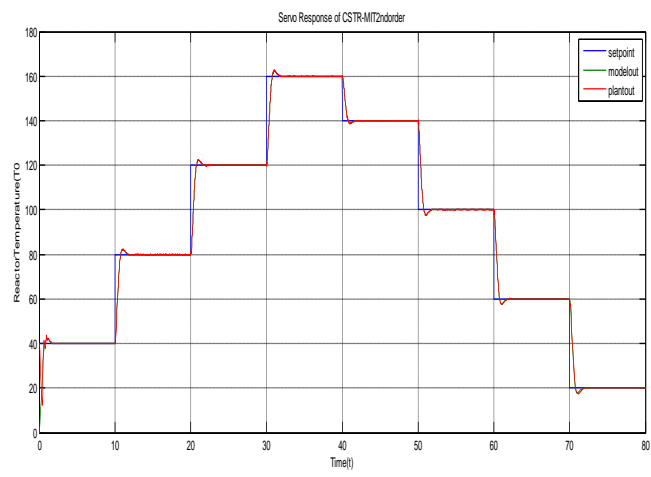

Fig: 5 Servo response of an MRAS with MIT rule with 2nd order reference model

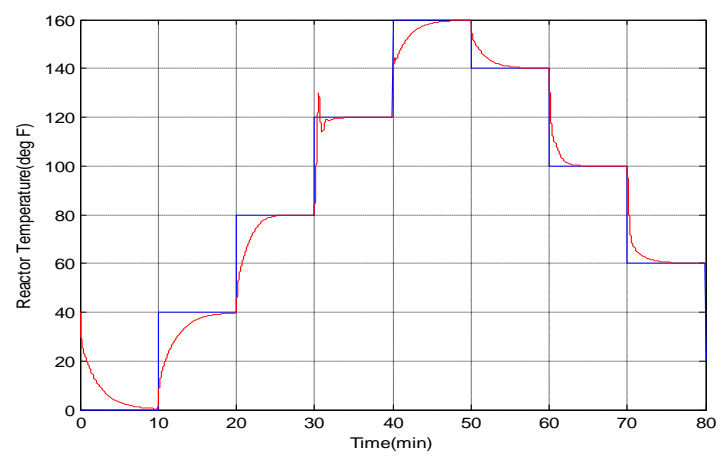

Fig:6 Servo response of a nonlinear PI controller 
Table 3: Comparison of performance of MRAS and Conventional PI controller

\begin{tabular}{|c|c|c|c|c|}
\hline $\begin{array}{c}\text { Operating } \\
\text { Points } \\
{ }^{\circ} \mathbf{F}\end{array}$ & Controller & $\begin{array}{c}\text { Settling } \\
\text { Time } \\
\left(t_{s}\right) \\
\text { min }\end{array}$ & $\% \mathbf{M}_{p}$ & ISE \\
\hline 40-80 & \multirow{3}{*}{$\begin{array}{c}\text { Conventional } \\
\text { PI }\end{array}$} & 6.3 & NIL & 506.4 \\
\hline $80-120$ & & 4.2 & 8.3 & 412.3 \\
\hline $120-140$ & & 8 & NIL & 862.2 \\
\hline $40-80$ & \multirow{3}{*}{$\begin{array}{l}\text { MIT Rule } \\
\text { (with 1st } \\
\text { order ref } \\
\text { model) }\end{array}$} & 3.95 & NIL & 299 \\
\hline 80-120 & & 3.96 & NIL & 307.4 \\
\hline $120-140$ & & 3.5 & NIL & 307.5 \\
\hline $40-80$ & \multirow{3}{*}{$\begin{array}{l}\text { MIT Rule } \\
\text { (with 2nd } \\
\text { order ref } \\
\text { model) }\end{array}$} & 3 & 2.6 & 300.5 \\
\hline $80-120$ & & 3 & 2.6 & 307.4 \\
\hline $120-140$ & & 3 & 2.6 & 307.4 \\
\hline
\end{tabular}

\section{CONCLUSION}

A Model Reference Adaptive System strategy has been developed for CSTR, which involves mechanisms to adapt itself for nonlinearities in the system. The performance of MRAS and conventional PI control are evaluated by classical performance indices like settling time, overshoot and ISE. The result shows that the Model Reference Adaptive System outperforms the conventional PI controller. The MRAC is designed with transfer function models can be replaced with fuzzy/Neural model could be the future scope of the present idea.

\section{REFERENCES}

[1] M. Nakamura, T. Sugi, and S. Goto, "Nonlinear separation model and control for a complex process realized by conventional PID controller hardware," in Proc. 4th Asian Control Conference, Singapore, 2002, pp. 274-279.

[2] Karl J. Astrom, Adaptive Control, Pearson education, Second Edition, 2006

[3] B. Wayne Bequette. Process Control, modeling, design, and simulation. Prentice Hall of India, First Edition 2004.

[4] Katsuhiko Ogata, Modern control engineering, Prentice Hall of India, Third Edition 1997.

[5] P. Dostál, J. Vojtěšek, and V. Bobál, "Simulation of adaptive control of a continuous stirred tank reactor," in Proc. 23rd European Conference on Modelling and Simulation, ECMS 2009, Madrid, Spain, 2009, pp. 625630.

[6] A. Astolfi, D. Karagiannis, and R. Ortega, Nonlinear and adaptive control with applications. London: SpringerVerlag, 2008 